Janja Vollmaier Lubej

\title{
Sodobna ukrajinska migrantska problematika $v$ luči evromajdanskih protestov in vojne
}

Ključne besede: evromajdan, Ukrajina, notranje razseljene osebe, vojni begunci, ekonomski migranti, posledice vojne, patriotizem.

DOI: $10.4312 /$ ars.10.2.63-78

\section{1 Čas majdana in odzivi nanj}

Vidnejši sodobni ukrajinski pisatelj, pesnik, esejist in prevajalec Jurij Andruhovič (1960) je leta 2006 prejel nagrado leipziškega knjižnega sejma za evropsko razumevanje. ${ }^{1}$ V svojem govoru s pomenljivim naslovom Evropa - moja nevroza je izpostavil izjavo ukrajinskega klasika Ivana Franka (1856-1916): »Tudi mi smo Evropa.« Andruhovič problematizira to Frankovo predpostavko, ki je po toliko letih še kako aktualna. Zanj je to »osamljen klic v temi«, potreba po ponovitvi te izjave pa je v današnji resničnosti še vedno prisotna (Andruhovič, 2006). Vključevanje ukrajinske družbe v Evropo in evropsko priznavanje ukrajinske evropskosti se tako uresničuje že stoletja, ne da bi se zares uresničilo. Andruhovičev glas je eden redkih, ki opozarja na absurdna dejstva, med katera sodi na primer neovirano gibanje oziroma potovanje Ukrajincev po Evropi. Sprašuje se, ali se Evropa boji sebe in drugih ter ali je njena vrednota nesposobnost za spremembe. Številni najsodobnejši dogodki, kot so na primer priključitev Krima Rusiji, vojna na vzhodu države in migrantska problematika, ter odzivi nanje pričajo o tem, da se je Evropa že zdavnaj odpovedala osnovnim človekovim pravicam in da je še bolj kakor prej vzpostavila trdno mejo med Vzhodom in Zahodom. Evropske vrednote, za katere so si prizadevali evromajdanski protestniki, ${ }^{2}$ so obrnile hrbet prav tem ljudem, ki so se borili zanje. Tako je danes Ukrajina priča veliki politični, gospodarski in humanitarni krizi. Ta je v javnih diskurzih, kjer prevladujejo patriotske teme, vojna in korupcija, vse premalo poudarjena.

Najsodobnejša ukrajinska zgodovina je zaznamovana s tragičnimi dogodki iz leta 2013, ko so ljudje v evromajdanskem gibanju množično protestirali, tudi s smrtnimi žrtvami, na Trgu neodvisnosti (Majdanu nezaležnosti) v Kijevu, kjer je bilo mogoče

1 Leipziger Buchpreis zur Europäischen Verständigung.

2 Evromajdan označuje proteste proti vladajoči eliti in korupciji, ki jih je povzročila Janukovičeva zavrnitev podpisa pridružitvenega sporazuma med Evropsko unijo in Ukrajino. 
opaziti »majhno zrcaljenje Evrope« (Plahonin, 2016, 26), »revolucijo srednjega razreda, meščanstva proti postsovjetskemu sistemu nekega oligarhičnega kvazifevdalizma" (Rjabčuk, 2014a, 153), in v drugih večjih ukrajinskih mestih, da bi izrazili svoje nestrinjanje $\mathrm{z}$ Janukovičevim zavračanjem ukrajinskega približevanja Evropski uniji. Jasno pa je, da je bil to le en in ne osrednji vzrok za množične demonstracije. Po razpadu Sovjetske zveze je namreč Ukrajina kot nova, neodvisna država "postala žrtev nekdanje nomenklature, ki je sanjala o nacionalni neodvisnosti in se hkrati za to ni nikoli borila« (Rjabčuk, 2014a, 153). V državi je prišlo do stagnacije, frustracije in dramatičnega razpada družbe (prav tam). Država je v času Janukovičevega vladanja postala oligarhija (Snyder, 2014, 132), a opozoriti je treba, da je temu zelo podobna tudi danes, potem ko je bil na demokratičnih volitvah po demonstracijah izvoljen Petro Porošenko, čokoladni kralj in lastnik off-shore podjetij. Ukrajina namreč tudi pod njegovim vodstvom tone $\mathrm{v}$ vse večje gospodarske in politične težave. Čas Janukovičevega predsednikovanja je bil čas »brutalnega in ciničnega« (Maljarčuk, 2014, 82), neomejeno je vladalo »načelo močnejšega« (prav tam). Janukovič »ni bil vzrok, temveč le posledica razpada ukrajinske družbe, njene apoteoze« (Maljarčuk, 2014, 83). Po množičnih protestih, ki so odraz naveličanosti nad dolgotrajno neumeščenostjo države, ki predstavlja t. i. »sivo cono med postsovjetsko avtokracijo na vzhodu in demokratičnimi sosedi na zahodu“ (Rjabčuk, 2014b), se Ukrajina ni približala Evropi in tudi ni prišlo do pomembnejših premikov v to smer, saj ukrajinska politika ni izvedla za to potrebnih reform. Država pa se ob tem še vedno sooča s korupcijo, brezposelnostjo in nizkimi dohodki, zaradi česar številni ljudje tonejo v vse večjo revščino in brezizhodnost.

Ni nezanemarljivo, da je evrorevolucijo sprožil Mustafa Najem, musliman, Afganistanec (Snyder, 2014, 134), ki se mu je kmalu pridružilo na milijone ljudi različnih nacionalnosti in veroizpovedi. Ko so se miroljubni protesti sprevrgli v nasilje, je bila skupaj s številnimi žrtvami pokopana tudi ideja, za katero so se protestniki zavzemali. Ljudje, ki so verjeli v evropske vrednote in se zavijali v evropske zastave, so kmalu spoznali, da »evropsko ozvezdje na hrbtih ne napoveduje nič več kot razočarana pričakovanja imaginirane Evrope« (Miščenko, 2014, 22).

\section{Evropa v Ukrajini in Ukrajina v Evropi}

$\mathrm{V}$ času majdana in po njem so se pojavili številni humanistični odzivi ter razprave o njegovih vzrokih in posledicah, nastalo je ogromno najrazličnejših besedil na to temo oziroma se je uresničil »besedilni produkcijski stroj« (K. R., 2014, 203), saj so se vzpostavili številni blogi, pojavile so se objave na socialnih omrežjih, članki, reportaže itd. (prav tam), v katere se je vključilo mnogo ukrajinskih in tujih 
intelektualcev, kulturnikov in umetnikov. Predvsem so se številni avtorji ukvarjali z vprašanjem evropskosti v ukrajinski družbi in nasprotno, $\mathrm{z}$ vprašanjem o Ukrajini v Evropi, ter tudi s sovjetskimi ostalinami v neodvisni ukrajinski državi in njihovimi posledicami.

Evropa se je (in se v veliki meri še) do ukrajinske politične krize obnašala ignorantsko, sanjaško, sanjavo: »Zaprla je oči. [...]. Ko se zbudi, se ne spominja več svojih sanj, ne razume, da Ukrajina ni več oddaljeno obrobje, temveč prizorišče dramatičnih evropskih sprememb« (Miščenko, 2014, 36). A Ukrajina sama se v zadnjih letih v resnici ni približala Evropi, o čemer s kritično ostrino piše že omenjeni Andruhovič: „Smo v resnici dosegli uspehe? Si to resnično zaslužili? Je pri nas več svobode? Ali smo preprosto pričakovali, da nam ga [vstop v Evropo, op. a.] bodo kar poklonili?« (Andruhovič, 2015a, 201). In dodaja: »Nobeni licemerski podpisi nekakšne pogodbe ne bodo rešili naše usode, samo mi jo lahko rešimo« (prav tam).

Veliko je bilo odzivov ukrajinskih in tujih intelektualcev na vojno, diktatorstvo Viktorja Janukoviča, proteste in njihove žrtve. Eden takih odzivov je odprto pismo Jurija Andruhoviča, od tujih pa je vredno izpostaviti poziv intelektualcev, med drugim Aleša Debeljaka, Slavoja Žižka, Adama Zagajewskega, Adama Michnika, Andrewa Arata itn., v katerem je jasno poudarjena misel, da ne smejo obrniti hrbta Ukrajini. Zavedajo se morebitnega diktatorskega režima $\mathrm{v}$ državi, ob tem pa poudarjajo, da ni prepozno, da bi Ukrajinci to spremenili. Zaradi demokracije je treba podpreti in krepiti neodvisnost in pluralnost medijev v Ukrajini. Nasprotovanje nekdanji ukrajinski vladi ter poziv $\mathrm{k}$ ukinitvi brezzakonja in nasilja nad ljudmi je izrazil tudi ukrajinski odbor PEN-a (Flood, 2014). Maja 2014 se je v Kijevu odvijala odmevna mednarodna konferenca $\mathrm{z}$ naslovom Ukraine: Thinking Together, na kateri so ugledni intelektualci, med drugim Timothy D. Snyder, Slavenka Drakulić, Bernard-Henri Lévy, Paul Berman idr., predstavili evropsko preteklost Ukrajine, Ukrajino v evropski resničnosti, balkansko vojno in vlogo intelektualcev v njej ipd. Potem ko Jurij Andruhovič v že omenjenem pismu predstavi delovanje nekdanje diktatorske oblasti, poda nekaj humanističnih prepričanj, kot sta vztrajanje pri protestih zaradi nestrinjanja $\mathrm{z}$ življenjem $\mathrm{v}$ državi, »ki se je spremenila v vseživljenjski zapor« (Andruhovič, 2014), ter zavračanje nasilja, ki se je razvilo iz sprva miroljubnih protestov, pri čemer je bila »zakonita osnova« za takšno ravnanje ustvarjena v parlamentu, kjer se je izvršila »primitivna kršitev vseh pravil postopkov in volitev, dejansko pa ustave same« (prav tam). Zaradi zagovarjanja evropskih vrednot so bili njihovi zagovorniki kaznovani $\mathrm{z}$ mučenjem in izginotji, $\mathrm{v}$ Ukrajini se je s tem zgodil »velik zločin proti človeštvu«. Andruhovič jasno poudari, da so protestniki branili »evropske vrednote za odprto družbo s svojo krvjo« (prav tam). Najbolj tragično je, da se v ukrajinski družbi ni veliko spremenilo in da so žrtve ostale le še mit dovčerajšnje preteklosti. Ne le to, zdi se, da se vedno znova ciklično 
vzpostavlja krogotok krute zgodovine, o čemer na primer piše poljski intelektualec in urednik Adam Michnik (2014) ob primeru Krima. Utemeljitve za njegovo priključitev Rusiji primerja z utemeljitvijo nacističnega režima, v okviru katere je Adolf Hitler »ognjevito izražal zaskrbljenost za dobrobit svojih rojakov, ki živijo pod tujo oblastjo« (prav tam).

Andrej Kurkov, prav tako pomemben ukrajinski pisatelj, je v obdobju protestov pisal dnevnik o življenju med revolucijo, ki je izšel tudi v nemškem, angleškem in francoskem prevodu. Prepričan je, da je Evropa »zapustila Ukrajino« (Flood, 2014), pri čemer je izpostavil, da državi hrbta nista obrnili le Litva in Poljska. Izrazil je tudi humanistično prepričanje, da »tisti, ki streljajo prvi, nikoli ne berejo knjig. Politiki zelo malo berejo. V Rusiji in Ukrajini še zlasti ne« (Soban, 2014).

O resnični oddaljenosti med Evropo in Ukrajino priča izjava: »Ukrajina in Evropa sta mesečnika, med katerima nenadoma stoji povsem drugačen schengenski zid « (Miščenko, 2014, 36). Skrajna ignoranca v odnosih Evropske unije do Ukrajine se je zelo jasno pokazala ob protestih, na kar opozarja novinar Branko Soban:

Evropska unija je v odnosih s Kijevom doslej zamudila vse, kar se je zamuditi dalo. Oranžna revolucija pred desetimi leti je bila imenitna priložnost, da Bruselj s konkretnimi ponudbami Ukrajino vendarle spodbudi k temeljitim političnim in gospodarskim reformam. Toda Bruselj ni ponudil ničesar. (Soban, 2014).

Izkazalo se je, da se po evromajdanu ni zgodil noben, ne družbenopolitični ne kulturni premik, ne pomik k evropskim vrednotam, in dogajanje po tragičnih dogodkih lahko strnemo z izjavo uglednega novinarja Andrija Plahonina: »Kakor prej smo Evropejci le v besedah, kar zadeva uresničevanje izrečenega, pa se le malo razlikujemo od vzhodnih sosedov« $(2016,26)$.

\subsection{Posledice protestov - notranje razseljene osebe}

Množični protesti, ki so se zavzemali za evropske vrednote, so povzročili ne le številne smrtne žrtve, ki jih je ukrajinski javni diskurz poimenoval nebeška stoterica, in še vedno trajajočo vojno na vzhodu države, temveč tudi poudarjanje nacionalne identitete, ukrajinščine, kulturne dediščine in kulture $\mathrm{v}$ najširšem smislu, ne le znotraj Ukrajine, temveč tudi zunaj njenih meja, kar se kaže v obuditvi ukrajinske diaspore (Düvell, Lapšina, 2015). Zlasti pa se je ob tragičnih dogodkih znova in jasno vzpostavilo temeljno vprašanje o vlogi in pomenu Ukrajine v Evropi (in nasprotno) ter obuditev tragičnih dogodkov sovjetske preteklosti, ko je režim prisilno deportiral krimske Tatare. Zelo podobno, le v veliko manjšem obsegu, se to dogaja tudi danes, po priključitvi Krima Rusiji. Po podatkih je 20.000 Krimčanov prisilno zbežalo v 
notranjost Ukrajine, 17.000 pa je razseljenih oseb znotraj Krima (Düvell, Lapšina, 2015). OVSE jasno piše, da so bili krimski Tatari prisiljeni v preselitev, in sicer zaradi velikega strahu pred represijo, vključno z zmanjšano pravico do zborovanja, izobraževanja, nasilniških izginotij, preganjanj aktivistov ... (Düvell, Lapšina, 2015). Protesti so prav tako izzvali premišljevanja o težavah in izzivih sodobne Ukrajine, ki se sooča $\mathrm{Z}$ »endemično korupcijo (Düvell, Lapšina, 2015) in trajno ekonomsko krizo. Pričujoči prispevek pa se podrobneje ukvarja s še eno posledico poosamosvojitvene in pomajdanske Ukrajine, to je z migracijami tako znotraj države kot zunaj njenih meja.

Po podatkih iz leta 2015 je bilo notranje razseljenih oseb okoli 1,3 milijona, 60 \% je žensk in otrok (Rössler, 2016), 900.000 pa je bilo tistih, ki so migrirali prek ukrajinskih meja, v glavnem v Rusijo in Belorusijo (Düvell, Lapšina, 2015). Začetni val notranjih migracij je potekal $v$ zahodnem delu Ukrajine, nato pa so se begunci ustalili znotraj Doneške, Luganske in Harkovske regije, prihajali so tudi v Kijev. Regije na vzhodu države so končni cilj $80 \%$ vseh razseljenih oseb (Jaroszewicz, 2015). Več predstavnikov nevladnih organizacij poroča o pomanjkljivi državni pomoči notranjim migrantom ter o težavah oziroma diskriminaciji pri iskanju stanovanja in zaposlitve (Rössler, 2016). Po drugi strani je mogoče opaziti, da je odnos ljudi do notranje razseljenih na splošno pozitiven ali nevtralen (prav tam). Zaznati pa je mogoče tudi nekatere predsodke, s katerimi smo se srečevali ob zadnjih migracijah Sircev, ko se je domala povsod širil neutemeljen strah nehumane, nestrpne družbe. Tudi v ukrajinski družbi so občutja glede notranje razseljenih oseb ambivalentna. Moškim na primer namenjajo obtožbe, da bi se morali vrniti in se bojevati za ukrajinsko državo (Rössler, 2016). Izmed vseh notranje razseljenih oseb so največ neodobravanja deležni Romi, ki so jih sicer negativno sprejemali že prej, tj. pred politično krizo v državi (Rössler, 2016). Vredno pa je poudariti, da se na migracijsko in politično krizo odzivajo tako civilne pobude kot tudi kulturne organizacije. V Kijevu se je problematiki pomajdanskih notranjih migracij posvetil festival dokumentarnega filma Docudays 1, na katerem je bilo predstavljenih več kot 90 filmov na teme človekovih pravic, migracij, pravičnosti, vojne in miru (Rössler, 2016). Umetnost je hotela preseči stisko, a takšnih odzivov ni bilo zelo veliko.

Organizacijski komite dokumentarnega filma v Kijevu je izrazil skrb zaradi notranje razseljenih oseb in poudaril, da se je »država [...] znašla v iluziji, da se bodo ljudje znašli sami. Notranje razseljene osebe pa živijo v iluziji, da se bodo kmalu vrnile v domače kraje in tam živele kot prej« (Rössler, 2016). V nadaljevanju ostro obsodijo pasivnost države, pomanjkljive programe za vključevanje beguncev ipd. (prav tam). Na neodzivnost in neorganiziranost države pri pomoči notranje razseljenim osebam opozarjajo tudi novinarji, prostovoljci in mednarodne organizacije. Nekateri ukrajinski 
mediji ${ }^{3}$ so se ukvarjali $\mathrm{z}$ migrantsko problematiko, pri čemer so večinoma opozarjali na težave in nesprejetost migrantov ter na neodzivnost države. Predstavljali so zgodbe notranje razseljenih oseb in njihove glasove. Na spletnem portalu Ukraine today so novinarji posneli krajše reportaže, intervjuje ipd. Opozarjajo na posttravmatski stres pri demobiliziranih moških in na posledice nezdravljenih travm. Ukvarjajo se s številnimi notranje razseljenimi osebami, ki so zbežale s Krima oziroma konfliktnih območij na vzhodu Ukrajine, $\mathrm{z}$ njihovimi finančnimi težavami in birokratskimi zapleti (Moroz, Vinogradova, 2015). Več kot jasno je, da vlada s svojo pomanjkljivo politiko ne pomaga beguncem na novo zgraditi njihovih življenj, in videti je, da je država pri tem povsem odpovedala. Tega se zavedajo tudi sami begunci. Na primer, Irina Magricka, prav tako begunka iz Donecka, je za Radio Free Europe / Radio Liberty »kritizirala Kijev zaradi neizpolnjenih obljub in zanikanja naraščajočega problema $\mathrm{z}$ notranje razseljenimi osebami« (Ukraine Refugee Crisis, 2015). Dalje, UNHRC ocenjuje, da se država ne zna soočati s krizo. Poudarjeno je tudi, da ukrajinsko begunsko krizo zahodni mediji v luči množičnih migracij iz Bližnjega vzhoda in Afrike ignorirajo (Ukraine Refugee Crisis, 2015). Ni nepomembno izpostaviti, da situacijo rešujejo humanitarne, dobrodelne, neprofitne in nevladne organizacije, ki trdijo, da »Evropa z ignoriranjem ukrajinske bede kot mesečnik vstopa $\mathrm{v}$ humanitarno katastrofo, ki lahko hitro uide izpod nadzora» (Ukraine Refugee Crisis, 2015).

Največje žrtve vojne so otroci. Zaradi vojne se je povečalo število otrok, nastanjenih v sirotišnicah oziroma centrih. Za otroke zaradi pomanjkanja sredstev ni ustrezno poskrbljeno v nobenem pogledu (hrana, namestitev, psihosocialna pomoč itd.) (Ukraine’s Forgotten Children, 2015). Sirotišnice so prenapolnjene, pomagajo jim prostovoljci, primanjkuje jim državnih sredstev in nimajo denarja niti za hrano.

$\mathrm{V}$ vojno je po ocenah vpletenih več kot pet milijonov ljudi, od tega 1,7 milijona otrok (Unicef Deputy representative in Ukraine, 2015). Kakšno sporočilo dajemo tem otrokom, njihovi in tudi naši prihodnosti? Rudi Luchmann, predstavnik UNICEF-a za Ukrajino, je prepričan, da se v vsakdanjih novicah ne sliši otrok, razseljenih znotraj Ukrajine. Gre za »nespoštovanje otrokovih pravic« (Unicef Deputy representative in Ukraine, 2015). Notranje razseljeni se počutijo osamljene in zapuščene, preveva jih občutek, da so nanje vsi pozabili. Dokumentarni film Returning Home avtorja Stanislava Jasinskega iz leta 2015 podaja resnično podobo žrtev vojne ter posebno pozornost namenja zapuščenim in osamljenim otrokom. Tako je torej videti, da so

3 Osrednji ukrajinski mediji, na primer časopisa Den in Gazeta, ukrajinski spletni portal Ukraine Today, prispevki Radia Free Europe ter prispevki tujejezičnih objav (Ukraine Refugee Crisis, Rössler, UNHRC itn.) predstavljajo problematiko notranje razseljenih oseb in opozarjajo na pomanjkljivo vladno pomoč ter ignoranco ukrajinske države do njihovih travm. Mediji se bodisi osredinjajo na posamezne zgodbe bodisi problematiko razširjajo in poglabljajo ter nastopajo $\mathrm{v}$ vlogi demokratičnega glasu utišanih in zapuščenih. 
ob majdanu in vojni sicer nastala številna besedila, odzivi, pogovori in konference vidnejših ukrajinskih in drugih intelektualcev, kulturnih delavcev, politologov in novinarjev, medtem ko se s posledicami vojne, zlasti s prisilnimi migracijami znotraj in zunaj države, še posebno pa $\mathrm{z}$ otroki in drugimi ranljivimi skupinami, omenjeni odzivi niso veliko ukvarjali. Problem t. i. prekomernega poročanja o vojni in pomanjkljivega poročanja o humanitarni krizi so izpostavili tudi avtorji knjižice Understanding information and communication needs among IDPs in Eastern Ukraine. Trapped in a propaganda war. Abandoned. Frustrated. Stigmatized (Ouintanilla, Parafeniuk, Moroz, 2015, 11), ki je izšla februarja 2015. Na naslovnici je predstavljena lokalna prostovoljna skupina Srce Slovjanska, ki nudi hrano in pomoč notranje razseljenim osebam v Svjatogorsku v Doneški regiji. Mesto nudi dom okoli 9.000 notranje razseljenim osebam (Ouintanilla, Parafeniuk, Moroz, 2015, 12). Fotografija ponazarja, kako je država povsem odpovedala; če ne bi bilo ljudi, ki ves teden požrtvovalno iščejo in prosijo za hrano, da bi jo razdelili razseljenim osebam, bi te poleg izgubljenega dostojanstva ostale še brez zadostitve osnovnih življenjskih potreb. Poleg pomanjkljivega financiranja s strani države ter pomanjkanja informacij pri pridobivanju pomoči je mogoče čutiti tudi socialne napetosti, stigmatiziranje in diskriminacijo (Ouintanilla, Parafeniuk, Moroz, 2015, 5), notranje razseljeni pa se zaradi države in vlade, ki se do njihovega položaja obnašata ignorantsko, počutijo zapuščene, travmatizirane in šokirane (Ouintanilla, Parafeniuk, Moroz, 2015, 9). »Posebno zaskrbljujoč dejavnik je globoko zakoreninjen občutek ,zapuščenosti notranje razseljenih oseb, ki čutijo, da jim vlada ne pomaga «(Ouintanilla, Parafeniuk, Moroz, 2015, 6-7). Država ne samo, da zanje ne poskrbi v dovoljšnji meri, temveč jim otežuje in celo onemogoča uresničevanje državljanskih pravic - leta 2015 jim na primer ni omogočila udeležbe na lokalnih volitvah, kar je v demokratični družbi posebej alarmantno. Dalje, »država je od decembra 2014 na območjih, ki jih nadzirajo proruski uporniki, znižala financiranje javnega sektorja, prav tako pa je tam odstranila bankomate in prekinila druge finančne storitve« (Ouintanilla, Parafeniuk, Moroz, 2015, 9). Nič nenavadnega, da so razseljene osebe zmedene in celo ujete $\mathrm{v}$ okoliščine, saj jim je poleg naštetega onemogočen prosti prehod na območjih, ki niso pod vladnim nadzorom: za to potrebujejo posebno dovolilnico (prav tam). Mediji se, z nekaterimi izjemami (gl. opombo 3), osredinjajo na vojno in patriotske uvodnike, le malo pa se ukvarjajo $s$ »humanitarno krizo in njenimi posledicami« (Ouintanilla, Parafeniuk, Moroz, 2015, 11-12). Glede na vse omenjeno je mogoče reči, da se sodobna obravnava ukrajinske situacije obsežno posveča predzgodbi, zgodovini in razvoju protestov, veliko je bilo izrečenega o vzrokih in posledicah (po)majdanske situacije, toda le malo besed je bilo izgovorjenih o ukrajinski migrantski problematiki, ki je tudi del teh posledic. 
Leta 2014 so države Evropske unije prejele 14.000 ukrajinskih vlog za status begunca, vključujoč 2.318 vlog na Poljskem. Istega leta je 859.000 Ukrajincev imelo potrdilo o prebivališču v Evropski uniji (Jaroszewicz, 2015). Glede na EASO je Ukrajince, ki iščejo mednarodno zaščito, mogoče razdeliti na dve skupini, in sicer na 1) posameznike, ki bežijo iz tistih vzhodnih delov države, ki ostajajo zunaj vladnega nadzora; 2) posameznike, ki se izmikajo vojaški obveznosti (Jaroszewicz, 2015, 3).

\subsection{Vzroki za ekonomske migracije}

Da je stanje v državi resnično skrb vzbujajoče, lahko razberemo iz zapisa že omenjene mlade pisateljice Tanje Maljarčuk (1983), potem ko je v svojem zadnjem prispevku pred selitvijo na Dunaj prepotovala dva tisoč kilometrov in na tej poti Ukrajince spraševala o ukrajinski neodvisnosti. Ni je presenetilo, da si ljudje niso predstavljali takšne Ukrajine, kakršna je danes, temveč spoznanje, da je njena domovina kot "gnusna rana, s strtimi ljudmi, ki ne poznajo lastne preteklosti in ne verjamejo v prihodnost « (Maljarčuk, 2014, 84). O težki situaciji Ukrajine beremo tudi v prispevku Michaela Mayerja Resendeja (2016), ki tematizira nepripravljenost ukrajinske politike, da bi odpravila anomalije v skorumpirani družbi. Sprva poudari, da "preoblikovanje Ukrajine ni enostavno« (2016) in da »celo v času miru to prenavljanje zoper oligarhični sistem pomeni težak napor« (prav tam). Četudi je mogoče opaziti nekaj pomikov v to smer, znaki katerih so na primer prenovljena, nepodkupljiva policija, protikorupcijski uradi ${ }^{4}$ in reformirani »industrijski monstrum«, kot je Naftogaz (prav tam), ni mogoče zaznati nobenih premikov pri eni od potrebnih reform, tj. decentralizaciji moči oz. vzpostavitvi učinkovite javne uprave (prav tam). Čeprav se kaže korak $\mathrm{k}$ izboljšanju na primeru sodne reforme, avtor prispevka poudari, da je uzakonjene reforme v Ukrajini težko uresničiti v praksi, kar je dokaz, da gre pri (ne)sprejetju za politično voljo (prav tam). Pomembno je poudariti, da se po majdanu ni zgodilo veliko, še več, država oziroma sodstvo je blokiralo preiskavo o pokolu na majdanu, prav tako ni bil preiskan požar v sindikalni stavbi v Odesi, kjer je maja 2014 umrlo več kot štirideset proruskih antimajdanskih protestnikov (Rössler, 2016). Vendar lahko razjasnitev teh majdanskih dogodkov, za katero se zavzema odvetnik Pavel Dikan, usmerja k pozitivnemu premišljanju o prihodnosti ukrajinske države in tudi omenjenega odvetnika predstavlja kot najsodobnejši ukrajinski glas, spremembo, ki vodi tudi k spremembi sistema (Rössler, 2016). Zaradi trenutno vse težjega življenja v domovini, nizkih dohodkov, brezposelnosti in brezizhodnosti iz tega položaja pa se številni Ukrajinci in Ukrajinke odločajo za preselitev v druge države. $V$ več kot dvajsetih letih je Ukrajina postala država $z$ eno največjih diaspor na svetu, ki obsega pet do šest milijonov ljudi (Düvell, Lapšina, 2015), pri čemer se

4 Ki pa jim zakon onemogoča preiskovati predsednika Porošenka, zato so imeli ob razkritjih panamskih dokumentov, v katerih se je znašel ukrajinski predsednik, zvezane roke. 
je množični val migracij začel po osamosvojitvi. A ta trend še ni upadel, saj je po podatkih število Ukrajincev v več kot dveh desetletjih (1991-2015) upadlo za dobrih devet milijonov (iz 52 na 42,9 milijona) (Düvell, Lapšina, 2015). Po majdanu, leta 2014, je mogoče opaziti povečano število Ukrajincev, ki so migrirali v Rusijo, leto kasneje pa je opazen porast migracij na Poljsko (Jaroszewicz, 2015). V prvi polovici leta 2015 je imelo veljavno prebivališče na Poljskem 400.000 Ukrajincev (prav tam). Začasne migracije na Poljsko postajajo vse bolj popularna rešitev iz revščine in nestabilnosti v Ukrajini (Jaroszewicz, 2015). Predvojne ekonomske migracije lahko razdelimo v dve obdobji, prvo obdobje je med letoma 2005 in 2008, ko je v tujini delalo 1,5 milijona Ukrajincev, pretežno v Rusiji, Italiji in na Češkem, medtem ko je v drugem obdobju, tj. med letoma 2012 in 2014, prišlo do porasta ukrajinskih delavcev v Rusiji in na Poljskem (Jaroszewicz, 2015). A to so statistični podatki, ki največkrat ne upoštevajo posameznika ter njegove osebne tragedije. Ob tem tudi ni mogoče zaslediti poglobljene in temeljite razprave o ljudeh, ki na primer na ukrajinsko-poljski meji čakajo kot drugorazredni državljani Neevrope, da bi vstopili v obljubljeno državo, ki jim kot velika dobrotnica nudi delo za dvesto, tristo dolarjev, nečloveške pogoje za bivanje ipd.

\subsection{Ekonomske migracije in niihove posledice}

Z množičnimi migracijami, ki jih doživlja sodobna Ukrajina, z ekonomskimi migracijami, ${ }^{5}$ ki po podatkih obsegajo okoli dva do tri milijone ljudi (The Economics), pri čemer 3,4\% ukrajinskega prebivalstva dela $\mathrm{v}$ tujini, $25 \%$ Ukrajincev pa po podatkih iz leta $2012 \mathrm{v}$ tujini dela ilegalno (Malinovska, 2006), se vzpostavljata vsaj dve posledici oziroma dva kompleksna problema ukrajinske družbe. To sta pomanjkljiva oskrba starejših in zapuščeni otroci. Mnogokrat namreč prvi skrbijo za svoje vnuke in nadomeščajo starše, četudi bi sami potrebovali pomoč in nego. Ukrajinski otroci so tradicionalno skrbeli za ostarele starše, saj v državi ni institucionaliziranega varstva starejših, ob sodobnih ekonomskih migracijah pa starejši niso deležni niti te pomoči (Malinovska, 2006). Opazimo torej trend, ko se je v novem tisočletju »nacionalna država odpovedala svojemu dolgu do nacije in namesto družbi blaginje pot odprla neoliberalnemu principu individualne odgovornosti za lastno ekonomsko in socialno usodo« (Vidmar Horvat, 2013, 177).

$\mathrm{Za}$ zapuščene otroke, prepuščene starim staršem ali sorodnikom, ima lahko odsotnost enega ali obeh staršev kljub izboljšanemu finančnemu stanju

5 Opazen porast delavskih migracij se kaže na Poljskem, zlasti zaradi jezikovne in kulturne podobnosti (Jaroszewicz, 2015, 5) ukrajinskih migrantov. Na Poljskem je veliko povpraševanje po delavcih v kmetijstvu in v zasebnih gospodinjstvih. Trend naraščanja števila delavskih migrantov je opazen zaradi preprostih in brezplačnih postopkov pri pridobivanju delovnega dovoljenja (prav tam). Podatki iz oktobra 2015 kažejo, da naj bi bilo ukrajinskih imetnikov potrdil o prebivališču na Poljskem 52.000, medtem ko je ilegalnih priseljencev okoli 300.000-500.000 (Jaroszewicz, 2015, 5). 
družine dolgoročne psihosocialne posledice in travme (Janovič, 2015). Otroci iz transnacionalnih družin so tudi bolj dovzetni za mladostniško prestopništvo, prekupčevanje z ljudmi, izkoriščanje ipd. (Janovič, 2015). S tem ko odsotni starši za odtujene otroke in svoje domove skrbijo $\mathrm{z}$ nakazili iz tujine, obenem povzročajo še večjo neenakost, državi pa omogočajo, da ne uresničuje svojega osnovnega cilja, tj. poskrbeti za svoje državljane ter za njihovo zdravstveno, socialno in izobraževalno dobrobit (Janovič, 2015). Recepcija takšnih migracij je v javnem in zasebnem diskurzu različna, in ker je v ospredju materialna varnost, se zdi, da je takšno stanje običajno in so se nanj vsi vpleteni privadili. Za žensko-mater je odločitev za ekonomsko migracijo težja, čeprav jo širša družba sprejema, »če je to premikanje povezano $z$ ekonomskimi, socialnimi ali emotivnimi potrebami kolektiva; kadar torej intimno materinstvo prenese na raven javnega materinjenja za skupnost (Vidmar Horvat, 2013, 173). Ker ženska-mati prinaša v dom denar, ker njeno žrtvovanje »simbolizira univerzalno materinsko skrb za otroka, ki mu mora poiskati boljše življenje« (prav tam), je njeno delo tako zasebno kot javno pozitivno sprejeto, četudi je v vseh drugih pogledih njena odločitev deležna »javne graje« (Vidmar Horvat, 2013, 176). Veliko ukrajinskih migrantk opravlja delo negovalk ali gospodinj in tako postajajo "transnacionalne matere (Vidmar Horvat, 2013, 176), ki predstavljajo novo figuro v obdobju na prelomu tisočletja, zlasti v letih 2004 in 2007 (prav tam). Vendar se pri migrantkah vzpostavlja dvojna krivda, postkolonialne feministične teorije namreč poudarjajo, da migrantke doživljajo dislokacije, ki so prevelike, »da bi jih lahko ohranile v skupni vezi pripadanja ženskemu svetu «(Vidmar Horvat, 2014, 21). Po R. S. Parreñas obstajajo štiri osnovne dislokacije: izguba polnega državljanstva, bolečina ločitve od družine, kontradiktorna razredna mobilnost in nepripadanje (prav tam). Matere migrantke so "pogosto soočene $z$ očitki, da ne upoštevajo dovolj potreb svojih otrok, čeprav trdo delajo ravno za njihovo ekonomsko in čustveno dobrobit. [...] Phoenix (2011) na podlagi intervjujev ugotavlja, da so transnacionalne matere pogosto podvržene občutku krivde, ki jim ga nalaga okolica, pa tudi lastni otroci« (Učakar, 2014, 182).

Pretresljivo je, da v Ukrajini prva ločitev otroka in starša traja od dveh do petih let, prav tako pa je skrb vzbujajoč podatek o vse pogostejših trajnih migracijah oziroma trajno odsotnih starših (Malinovska, 2006). Ob zavedanju, da je prihodnost države odvisna predvsem od mladih, njihovih kvalitet, znanj, svetovnega nazora in humanističnih stališč, so lahko posledice ekonomskih migracij staršev za posamezno družbo izrazito negativne. Sočasno postaja naraščajoč fenomen trgovina $z$ belim blagom, ki so ga v veliki meri deležne ženske, prodane kot spolne sužnje v Zahodno Evropo, na Balkan in Bližnji vzhod (Malinovska, 2006). 


\section{Zaključek}

V prispevku so predstavljeni vzroki in posledice sodobnih ukrajinskih notranjih in zunanjih migracij, pri čemer se besedilo osredinja na pojmovanje ukrajinske stvarnosti v kontekstu evropskosti oziroma obratno. Opazimo lahko, da številna besedila oziroma odzivi na najsodobnejše proteste, ki so se zgodili v Kijevu in drugih ukrajinskih mestih, podajajo ravno omenjeni vidik premišljevanj, medtem ko se $\mathrm{z}$ migrantsko problematiko ne ukvarja veliko avtorjev. Prav tako je premalo opozarjanja na nedelovanje državne migrantske politike, ki notranje razseljenim osebam ne nudi dovolj pomoči, po drugi strani pa se $\mathrm{v}$ državi krepi patriotizem, poudarjanje nacionalne identitete kot rešitve vseh težav, s katerimi se država sooča. Zdi se, da se na ta način vsi odmikajo od resnične humanitarne katastrofe in gospodarske krize. V proevropskem zahodnem delu Ukrajine je mogoče na vsakem koraku opaziti številne ukrajinske in evropske zastave oziroma simbole, razširile so se trgovine $\mathrm{z}$ narodnimi oblačili, višivankami, ki jih ljudje nosijo ne samo ob posebnih priložnostih. Prav tako se je zgodil proces dekomunizacije, številne ulice in mesta so preimenovali (npr. Leninovo ulico v Ulico Johna Lennona, Dnipropetrovsk v Dnipro), podrli Leninove kipe ipd. Oblast in njeni prebivalci se torej aktivno borijo proti vsemu, kar spominja na sovjetsko preteklost, s čimer se kažeta močna želja in težnja po evropski prihodnosti. A vse omenjeno ne bo rešilo opisanih težav, s katerimi se soočajo tako ekonomski kot vojni begunci oziroma notranje razseljene osebe. V ukrajinskem medijskem diskurzu pogrešamo razprave, prispevke in članke, ki bi s kritično distanco odločno opozarjali na vse večjo humanitarno katastrofo in nasprotovali nedelujoči državi. Pot do pravne, pravične in socialne Ukrajine je še zelo dolga, hkrati pa je osamljen ukrajinski klic, »tudi mi smo Evropa«, še naprej preslišan in utišan.

\section{Literatura}

Andruhovič, J., Evropa - moja nervoza, 2006, http://www.signandsight.com/ features/670.html [23. 6. 2016].

Andruhovič, J., Open Letter from Ukrainian Writer Yuri Andrukhovych, 24. januar 2014, http://www.neweasterneurope.eu/interviews/1061-open-letter-from-ukrainian -writer-yuri-andrukhovych [10.6. 2016].

Andruhovič, J., Iz cimi?! Ne duzhe in hotilosja, v: Andruhovič, J., Tut pohovani Fantomas, Brusturiv 2015a, str. 199-201.

Andruhovič, J., Taka bezcinna zagroza, v: Andruhovič, J., Tut pohovani Fantomas, Brusturiv 2015b, 224-226. 
Düvell, F., Lapšina, I., The EuroMaidan Protests, Corruption, and War in Ukraine: Migration Trends and Ambitions, 15. julij 2015, http://www.migrationpolicy. org/article/euromaidan-protests-corruption-and-war-ukraine-migration-trendsand-ambitions [1. 6. 2016].

Flood, A., Ukraine "abandoned" by Europe, says novelist Andrey Kurkov, The Guardian, 24. januar 2014, https://www.theguardian.com/books/2014/jan/24/ ukraine-europe-abandoned-andrey-kurkov-union-protesters [13. 6. 2016].

Janovič, L., Children Left Behind: The Impact of Labor Migration in Moldova and Ukraine, 2015, http://www.migrationpolicy.org/article/children-left-behindimpact-labor-migration-moldova-and-ukraine [1. 6. 2016].

Jaroszewicz, M., The migration of Ukrainians in times of crisis. Centre for Eastern Studies 187, 19. oktober 2015, str. 1-8. http://www.osw.waw.pl/sites/default/files/ commentary_187.pdf [1.6.2016].

Jasinski, S., Returnig Home, 2015, https://www.youtube.com/watch?v=7wXPilrmS2w [1. 6. 2016].

K. R., Spremna beseda, v: Euromaidan. Was in der Ukraine auf dem Spiel steht (ur. Andruhovič, J.), Berlin 2014, str. 203.

Магрицька, I., Для держави переселенці - це «зниклі безвісти», Radio Svoboda, 10. avgust 2015, http://www.radiosvoboda.org/content/article/27167448.html [25. 6. 2016].

Malinovska, O., Caught Between East and West, Ukraine Struggles with Its Migration Policy, 1. januar 2006, http://www.migrationpolicy.org/article/caught-betweeneast-and-west-ukraine-struggles-its-migration-policy [1. 6. 2016].

Maljarčuk, T., Mehr als einer, v: Euromaidan. Was in der Ukraine auf dem Spiel steht (ur. Andruhovič, J.), Berlin 2014, str. 81-89.

Mayer-Resende, M., Ukraine fatigue in spreading in Europe, 24. maj 2016, http:// www.euractiv.com/section/europe-s-east/opinion/ukraine-fatigue-is-spreadingin-europe/ [4. 6. 2016].

Michnik, A., The Specter of the Kiev Maidan is Haunting the Offices of the Kremlin, 3. marec 2014, https://newrepublic.com/article/116832/adam-michnik-ukrainemight-be-beginning-putins-end [14. 6. 2016].

Miščenko, K., Ein schwarzer Kreis, v: Euromaidan. Was in der Ukraine auf dem Spiel steht (ur. Andruhovič, J.), Berlin 2014, str. 21-37.

Moroz, K., Vynogradova O., Ukraine's IDP Crisis Worsens as Local Attitudes Harden, 2015, http://www.atlanticcouncil.org/blogs/new-atlanticist/ukraine-s-idp-crisisworsens-as-local-attitudes-harden [18. 6. 2016]. 
ОСТАПОВЕЦЬ, Г., ШУМІЛІН, О., «Тисячі вулиць отримали нові назви. Жодних протестів не було», Gazeta UA, 5. februar 2016, http://gazeta.ua/articles/ opinions-journal/_tisyachi-vulic-otrimali-novi-nazvi-zodnih-protestiv-nebulo/674340 [12.6. 2016].

Plahonin, A., Velikomalorosija, Den, 25.-26. marec 2016, str. 26.

Quintanilla, J., Parafeniuk, O., Moroz, V., Understanding information and communication needs among IDPs in Eastern Ukraine. Trapped in a propaganda war. Abandoned. Frustrated. Stigmatized, februar 2015, http://www.internews.org/ sites/default/files/resources/Internews_IDPS_EasternUkraine_2015-02-11.pdf [1. 6. 2016].

Rjabčuk, M., Dreizehn schlimmere Orte auf der Welt, v: Euromaidan. Was in der Ukraine auf dem Spiel steht (ur. Andruhovič, J.), Berlin 2014a, str. 149-158.

Rjabčuk, M., Zerstörte Illusionen, 2014b, http://www.iwm.at/read-listen-watch/ transit-online/zerstorte-illusionen/ [1. 6. 2016].

Rössler, M., Ukraine: Eine Woche Kiew, 26. maj 2016, http://www.civic-forum.org/de/ artikel/ukraine-eine-woche-kiew [6. 6. 2016].

Soban, B., Evromajdan. Čas je, da Viktor Janukovič za vselej odide na smetišče zgodovine. Delo, 24. januar 2014, http://www.delo.si/mnenja/komentarji/evromajdan.html [17. 6. 2016].

Snyder, T., Die Ukraine hinter dem Schleier der Propaganda, v: Euromaidan. Was in der Ukraine auf dem Spiel steht (ur. Andruhovič, J.), Berlin 2014, str. 131-139.

ТІЛЬНОВА, І., Декомунізація. Як на практиці?, Den, 23. junij 2015, http:/day.kyiv. ua/uk/article/podrobyci/dekomunizaciya-yak-na-praktyci [10. 6. 2016].

Učakar, T., Dom, domovina in identiteta: priseljenka v slovenskem prostoru, v: Ženske na poti, ženske napoti: migrantke $v$ slovenski nacionalni imaginaciji (ur. Vidmar Horvat, K.), Ljubljana 2014, 169-225.

Ukraine's "Forgotten Children": Ukrainian orphanages struggle to care for those displaced by war, Ukraine Today, 18. oktober 2015, http://uatoday.tv/society/ ukraine-rsquo-s-lsquo-forgotten-children-ukrainian-orphanages-struggle-tocare-for-those-displaced-by-war-515413.html [13. 6. 2016].

Ukraine Refugee Crisis: Europe sleepwalking into humanitarian disaster, Ukraine Today, 10. avgust 2015, http://uatoday.tv/society/ukraine-refugee-crisis-europesleepwalking-into-humanitarian-disaster-472447.html [19. 6. 2016].

UNICEF deputy representative in Ukraine about children of war, Ukraine Today, 11. junij 2015, http://uatoday.tv/society/unicef-ukraine-deputy-representative-talksabout-children-of-war-in-estern-ukraine-436984.html [18. 6. 2016]. 
Vidmar Horvat, K., Zamišljena mati: spol in nacionalizem $v$ kulturi 20. stoletja. Ljubljana 2013.

Vidmar Horvat, K., Ospoljenje mej in teorije nacionalizma, v: Ženske na poti, ženske napoti: migrantke $v$ slovenski nacionalni imaginaciji (ur. Vidmar Horvat, K.), Ljubljana 2014, str. 17-36. 
Janja Vollmaier Lubej

\section{Sodobna ukrajinska migrantska problematika $v$ luči evromajdanskih protestov in vojne}

Ključne besede: evromajdan, Ukrajina, notranje razseljene osebe, vojni begunci, ekonomski migranti, posledice vojne, patriotizem

Članek se osredinja na ekonomske in politične begunce iz Ukrajine, ki se zaradi želje po boljšem življenju množično izseljujejo iz domovine, drugi pa so se zaradi vojne na vzhodu države prisiljeni razseljevati na varna območja znotraj nje. Članek predstavlja vzroke in posledice tovrstnih migracij zlasti $\mathrm{z}$ vidika humanističnih prepričanj, kakršna vidnejši ukrajinski literarni avtorji in avtorice podajajo $\mathrm{v}$ svojih esejih, premišljevanjih in zapisih (Jurij Andruhovič, Andrej Kurkov, Tanja Maljarčuk idr.), predvsem ob vprašanju evropskosti Ukrajine oz. ukrajinski (ne)prisotnosti v Evropi. Članek zanima tudi odslikava te problematike v javnem diskurzu, saj se zdi, da so te teme redkeje prisotne v primarnem smislu, poudarjeni pa so vzroki, ki so (tudi) privedli do današnje situacije: vprašanje nacionalnosti in identitete ter poudarjanje patriotizma. 
Janja Vollmaier Lubej

\section{Contemporary Ukrainian Migration Problems in a Light of Euromaidan's Protests and War}

Keywords: Euromaidan, Ukraine, internally displaced people, war refugees, economic migrants, consequences of war, patriotism

The present article focuses on the great numbers of economic and political Ukrainian migrants who have been migrating because of their desire for a better life or who have, forcibly, been internally displaced because of the war in eastern Ukraine. The article presents the reasons for and the consequences of the aforementioned migrations as evinced in the humanistic beliefs reflected in the essays, considerations and diary entries of esteemed Ukrainian writers (Jurij Andruhovič, Andrej Kurkov, Tanja Maljarčuk, etc.) - especially as have been observed in the light of Europeanism in Ukraine and the Ukrainian (non)-presence in Europe. The article is also interested in how this problematic is reflected in public discourse. It appears that the topic is less present in the primary sense, while emphasis is laid on the causes that led to the present situation: the question of nationality, identity, and the stressing of patriotism. 